University of Montana

ScholarWorks at University of Montana

Communication Studies Faculty Publications

Communication Studies

1988

\title{
Communication Between Physicians and Physical Therapists
}

\author{
Janet Bower Hulme \\ University of Montana - Missoula \\ Betsy Wackernagel Bach \\ University of Montana - Missoula, betsy.bach@umontana.edu \\ John W. Lewis \\ Columbus Hospital, Great Falls, MT
}

Follow this and additional works at: https://scholarworks.umt.edu/communications_pubs

Part of the Communication Commons

Let us know how access to this document benefits you.

\section{Recommended Citation}

Hulme, Janet Bower; Bach, Betsy Wackernagel; and Lewis, John W., "Communication Between Physicians and Physical Therapists" (1988). Communication Studies Faculty Publications. 1.

https://scholarworks.umt.edu/communications_pubs/1

This Article is brought to you for free and open access by the Communication Studies at ScholarWorks at University of Montana. It has been accepted for inclusion in Communication Studies Faculty Publications by an authorized administrator of ScholarWorks at University of Montana. For more information, please contact

scholarworks@mso.umt.edu. 

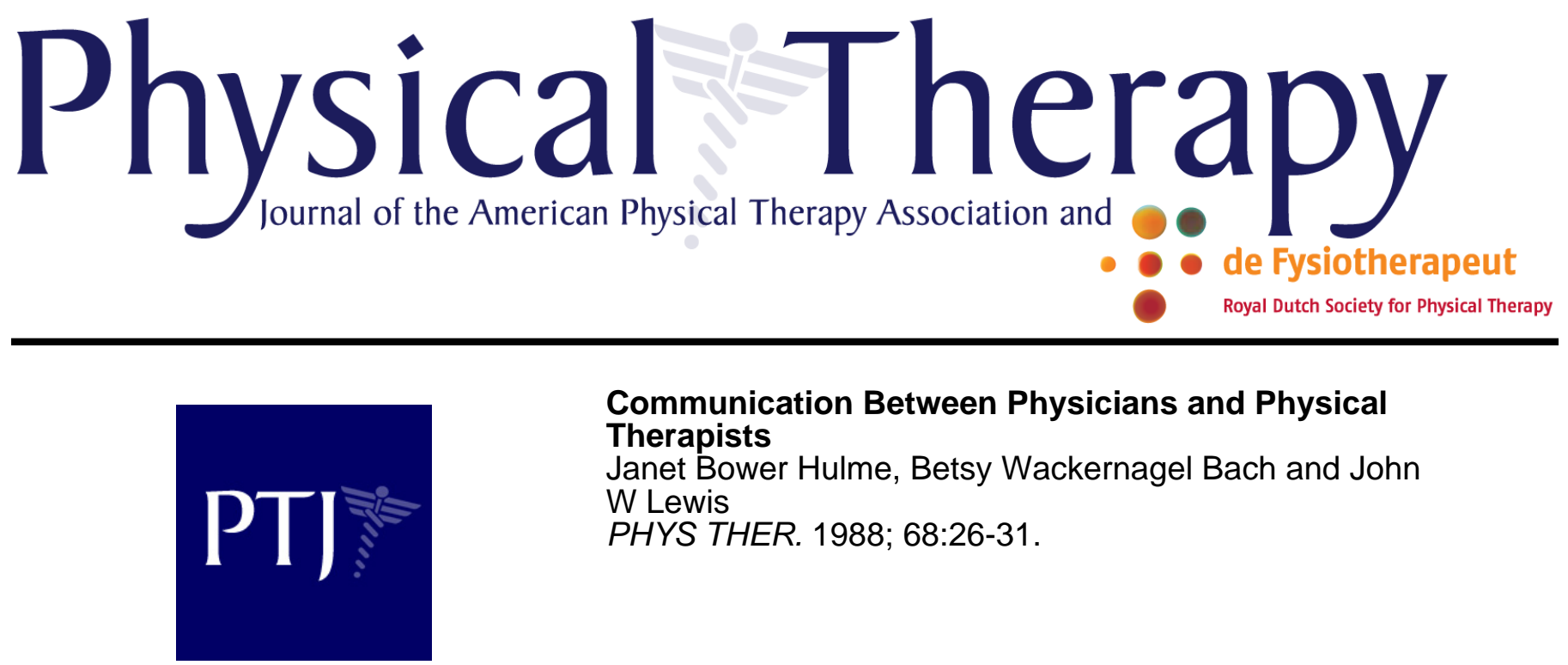

\author{
Communication Between Physicians and Physical \\ Therapists \\ Janet Bower Hulme, Betsy Wackernagel Bach and John \\ W Lewis \\ PHYS THER. 1988; 68:26-31.
}

The online version of this article, along with updated information and services, can be found online at: http://ptjournal.apta.org/content/68/1/26

\section{Collections}

e-Letters

E-mail alerts
This article, along with others on similar topics, appears in the following collection(s):

Coordination, Communication, and Documentation Professional Issues

To submit an e-Letter on this article, click here or click on "Submit a response" in the right-hand menu under "Responses" in the online version of this article.

Sign up here to receive free e-mail alerts 


\title{
Communication Between Physicians and Physical Therapists
}

\author{
JANET BOWER HULME, \\ BETSY WACKERNAGEL BACH, \\ and JOHN W. LEWIS
}

\begin{abstract}
The purposes of this study were 1) to identify therapists' and physicians' attitudes and opinions about the physician-physical therapist communication dyad, 2) to identify potential areas for improvement in this communication process, and 3 ) to provide physical therapists and physical therapy students with basic guidelines for optimal communications. Ten physical therapists and 8 physicians participated in individual interviews that were taped and subsequently transcribed. The transcriptions were compiled and analyzed by an interpersonal communication expert (B.W.B.) for trends and themes. Findings of the study include 1) physical therapists want increased accessibility to and communication with physicians and 2) physicians want brief communication with clear objective data provided by the therapists. Basic guidelines developed for physical therapy students as a result of this study include 1) identify physicians with whom you can communicate most easily, 2) learn your physicians' schedules, 3) organize beforehand so that communication is clear and concise, 4) be polite but self-assured, 5) ask your supervisor or other staff therapists for advice, and 6) use the telephone discriminately. This study emphasizes that communication with physicians must be approached on an individual basis. Each physician differs in personality, philosophy of patient care, and expectations of physical therapy. Therapists should take the initiative in developing good rapport and maintaining a viable relationship with physicians.
\end{abstract}

Key Words: Communication, Interpersonal relations.

A high standard of patient care is the goal of the medical team, and effective communication between the physician and the physical therapist is necessary to ensure this level of care. The socialization process of physical therapists does not always prepare them adequately for this communication role. In the early years of practice, it becomes progressively clearer to the new therapist that physicians, more than any other group, delineate the boundaries of responsibility and autonomy for physical therapists in delivering optimal patient care. The process is both direct and implied. ${ }^{1}$ Physical therapists currently face a changing role of autonomy and responsibility. The therapist has evolved from a technician who follows specific physical therapy prescriptions from physicians to a professional who evaluates the patient's needs, designs an appropriate treatment plan, and monitors the effects of the treatment. If a treatment plan does not solve the patient's problems, the therapist assumes a greater role in developing alternatives. Many therapists accept the physician's prerogative of issuing orders for treatment but want to be involved

J. Hulme, MA, is Associate Professor and Director, Physical Therapy Program, University of Montana, Missoula, MT 59812 (USA).

B. Bach, PhD, is Assistant Professor, Department of Interpersonal Communication, University of Montana.

J. Lewis, BS, is Staff Physical Therapist, Columbus Hospital, Great Falls, MT 59403. He was a student in the Physical Therapy Program, University of Montana, when this study was completed.

This article was submitted October 28, 1985; was with the authors for revision 55 weeks; and was accepted April 21, 1987. Potential Conflict of Interest: 4. in the evaluation and decision making that lead to these orders. Friedson states that patient management by physicians is not always directed or based on any systematic scientific knowledge but can be guided instead by occupational custom and folklore. ${ }^{2}$ The professional control of physical therapy by physicians may be unsubstantiated by specific medical knowledge of practice. As a professional, the physical therapist accepts the responsibility for the patient's well-being while the patient is in the therapist's care. In referring a patient to physical therapy, the physician is asking for assistance from another trained professional and is indicating that medicine and physical therapy differ. Physical therapists, therefore, have the responsibility to refuse to administer treatment when their professional experience suggests that it will be harmful.

The relationship between the physician and the physical therapist can be conceptualized as a process of negotiation. Individuals construct reality through negotiations with each other. ${ }^{3}$ In the medical setting, professionals base their actions to one another on their previously held perspectives, their understandings of how to act, and their expectations of how the person will act. ${ }^{4}$ The socialization process of physical therapists in the early years of practice is influenced by their interactions with physicians. Physician dominance emerged as the major problem for therapists in a hospital setting studied by Yarbrough. ${ }^{1}$ The perspectives developed through the recruitment and socialization processes of the physical therapists she studied apparently did not prepare them to 
assert their autonomy in a setting where the physicians' authority was primary and indisputable.

The results of Yarbrough's study indicated that therapists thought that they could 1) offer advice to physicians and 2) recognize the physicians' desire and need to be advised of changes in patients' treatments. ${ }^{1}$ The therapists, however, repeatedly charged the physicians with failure to respond to professional communications, especially telephone messages. In a study by Schonk-Boots, $85 \%$ of the physicians surveyed stated that they regularly read physical therapy progress notes in hospital charts, and $66 \%$ stated that they communicated with therapists verbally on a regular basis. ${ }^{5}$

In an article by Ross et al on the physician-physical therapist relationship, one therapist summarized the general consensus: "Physiomodalities should not be ordered by doctors; they should be on an assessment/treat as required basis with twoway communication." This two-way communication becomes very important with the emerging role of the therapist. The two professions clearly have expertise in different areas, but they complement each other. Ross et al stated, "Not a single therapist indicated a desire to break away from medicine or the medical model." 6

Throughout the socialization process (ie, classroom, internship, and first employment), the physical therapist interacts almost exclusively with other physical therapists, not with other health care professionals, in ongoing work relationships. ${ }^{1}$ This isolation has created an esprit de corps among therapists as a professional group, but it has weakened their ability to interact and negotiate with other disciplines. This limitation renders therapists less able to assert their authority in interactions with physicians. Therapists, thus, are in a less powerful position to respond to the needs of society and to provide the highest level of care.

Because time and space are limited in the physical therapy curriculum, students choose to learn information that is related directly to patient care. Thus, the skills needed for professional practice, such as negotiation strategies, are compromised. New graduates have had only limited learning experiences to help them understand the role of physicians or learn the skill to negotiate the care of patients within a team or with individual physicians.

Yarbrough states that, because of their relationship to physicians, therapists must negotiate the care of patients in a manner that does not challenge the physician's authority. ${ }^{1}$ This relationship requires physical therapists to be indirect and deferential in advising or recommending treatment. When approached in this manner, the physician thinks the suggestion is his and accepts it positively. ${ }^{7}$ The therapist who is direct and authoritative may be perceived as usurping patient control and taking the "captain's position." The physician thus feels insulted, interaction becomes strained, the rules are broken, and effective working relations break down.

The primary purpose of this study was to describe the expectations and perceptions of physical therapists and physicians concerning areas of communication essential to a high standard of patient care. These areas of communication include patient referral, patient progress, and patient treatment changes. A second purpose was to identify the perceptions of physical therapists and physicians concerning the professional relationship between their respective professional groups. The third purpose, based on concerns and problems in communication between the two groups, was to develop situational paradigms and guidelines for optimal communication between physicians and recent graduates or student therapists.

\section{METHOD}

\section{Subjects}

Eight male physicians and 10 physical therapists ( 5 men, 5 women) participated in this study. The physicians were selected based on their communication competency as perceived by experienced physical therapists in their community and by their frequency of referring patients to physical therapists. Three of the physicians were orthopedic surgeons, 1 was a neurologist, 1 was a psychiatrist, 2 were general internists, and 1 was a surgeon. Two of the physicians were from communities of about 10,000 people. The other six physicians were from communities of 30,000 to 50,000 people. One physician was a member of a physician-owned physical therapy service (POPTS). The others were in private practice with no physical therapist on site. The physicians had been practicing from 5 to 22 years $($ mode $=12$ ).

The physical therapists who participated in this study were recommended by an advisory committee of three physical therapists (each with a minimum of five years of clinical experience) who served as clinical advisors for research in areas of their clinical expertise. The advisory committee identified these physical therapists, who had been practicing from 1 to 19 years (mode $=8$ ), as competent communicators. Seven of the therapists worked in hospitals. Of these 7 therapists, 5 worked in hospitals with 120 to 122 beds and 2 worked in hospitals with 48 or fewer beds. Three of the therapists were in private practice, and one was in a POPTS. Two worked in communities with a population of 10,000 people or less. The other therapists were from communities of 30,000 to 50,000 people.

\section{Procedure}

Nine physicians and 11 physical therapists were contacted to participate in this study. One physician did not return phone calls and was dropped from the study; one physical therapist refused to participate. All remaining respondents expressed an interest and a willingness to participate in the study.

We used the interview method to collect data. ${ }^{8,9}$ Each physician and physical therapist was contacted by telephone to schedule an interview. The purpose of the interview was explained, and the interviewees were informed that their responses would be kept confidential. We solicited permission to record each interview at this time. All participants agreed to be recorded. About one week before the interview, an interview schedule and an outline of topics were mailed to the respondents so that they could prepare their responses before the interview (Appendix).

The third author (J.L.) conducted all interviews in the interviewee's office. Each interview ranged from 20 to 90 minutes. A pretest interview was conducted with a physical therapist (not included in this sample) to provide feedback about the interview content and format. All respondents received a letter of appreciation for their participation.

\section{Interview Construction}

We chose the interview method as the vehicle for data collection because it appeared to be the best way to assess physician and physical therapist communication. Spradley noted that the interview, particularly the ethnographic interview, allows researchers to understand human behavior. ${ }^{8}$ 
According to Spradley, ethnography yields empirical data about the lives of people in specific situations. These data allow us to perceive alternative realities and to modify our culture-bound theories of human behavior. ${ }^{8}$ Because this study assessed different perceptions of communication behavior, the interview method seemed to be the most appropriate method of data collection.

An advisory council of three physical therapists suggested interview questions for this study. These suggestions were rewritten into open-ended questions to allow an unbiased, free response from the interviewee. ${ }^{10}$ The topic of problems of communication between physical therapists and physicians, for example, was formulated into the question, "I am interested in how you perceive communication with physical therapists. What are your impressions of how you communicate with physical therapists and how they communicate with you?" These open-ended questions then were submitted to the advisory council for their final recommendations.

\section{Data Analysis}

After all interviews were conducted, the interviewer listened to the tape-recorded interviewee responses and noted key phrases and points made by each interviewee. Data were analyzed in three stages. First, we noted patterns and themes in the data. ${ }^{11}$ Statements that shared similar patterns and characteristics then were grouped together. Finally, we made conclusions by comparing and contrasting the clustered data. The last stage particularly was helpful in comparing and contrasting physicians' and physical therapists' perceptions of each other's communication competence.

\section{RESULTS}

\section{Essential Communication Areas}

The results of this qualitative study included physicians' and physical therapists' perceptions of their relationship and communication processes. Areas of communication that were assessed included patient referral, patient progress, and patient treatment changes.

Patient referral. The therapists and physicians we interviewed agreed that including the diagnosis during patient referral was a priority. Six therapists stated that it was very important, and three physicians stated that they included a diagnosis during patient referral. Physical therapists stated that, in many cases, the diagnosis was omitted or was vague and incomplete. Two therapists indicated that many of the listed diagnoses were actually symptoms and not diagnoses. "Shoulder pain," for example, is a symptom and not a diagnosis. The therapists stated, however, that even a preliminary diagnosis was important, because it can save the therapist time by giving them a starting place for evaluation, which allows the therapist to eliminate many pathological conditions that could cause the symptoms.

All of the therapists agreed that they preferred "evaluate and treat" instructions on physician referrals, which allowed them to use their professional judgment and training. We did not ask the therapists a specific question about evaluation, and they did not comment on their evaluation expertise in relation to the physician's referral. The therapists did state that they were the experts in physical modality use and exercise programs and that many of the physicians did not have the training or background necessary to prescribe specific modalities. The physicians varied on the specificity of their treatment prescriptions. One physician listed treatment goals that he wanted the therapist to accomplish. Another left the choice of treatment modality to the therapist. Two physicians specified the treatment modality to be used, but stated that it was meant to be more of a suggestion than a limitation to the therapist. One physician ordered specific treatment modalities and required the therapist to check with him before any change was made.

In summary, physical therapists recommended more complete information on diagnoses and less direction on modalities of treatment. Physicians varied widely on their delineation of a diagnosis and the control of treatment modalities.

Patient progress. The method and frequency of communicating with physicians about a patient's progress depended on several factors, including inpatient or outpatient status, acuteness or chronicity of the patient's condition, departmental policy, and the physician's preference. For inpatients, all therapists wrote daily progress notes filed in the hospital chart. Fifty percent of the physical therapists thought that physicians read progress notes regularly. One therapist stated that whether physicians read progress notes was difficult to determine because of the lack of feedback from the physicians. Seven physical therapists stated that daily progress notes were needed primarily in application for third-party payment. Many therapists felt that physicians did not read inpatient notes regularly, so they used other methods to update physicians. These methods included leaving a note on the front of the patient's chart, writing in the physician's progress note area, and contacting the physicians during their rounds.

Progress notes for outpatients and patients seen in private clinics were written at varying frequencies ranging from after every treatment daily to once a week. Four of the therapists mailed a written progress report to physicians if 1) an important change occurred in the patient's condition; 2) the patient's condition did not improve; 3 ) the referral period ended; or 4) a specified interval for reporting was established, such as every two weeks. These reports included a description of the patient's progress or lack of progress and recommendations to the physician about treatment changes and termination or continuation of treatment.

The physicians stated that they wanted to be notified 1) if the patient's condition changed, 2) at specified stages of the patient's treatment, and 3) if the patient was not doing well. Two of the physicians stated that they did not require an update if the patient was doing fine. "No news is good news" appeared to be their philosophy. Four of the physicians strongly advocated that the therapists should provide them with written, rather than verbal, reports. The physicians wanted legal documentation of patient progress. Two of the physicians thought that therapists should provide more objective data on a patient's progress to determine whether the therapy was helping and whether treatment should be continued. Three physicians stated that they relied on verbal updates of a patient's progress. The method of communication used depended primarily on the type of patient (ie, inpatient or outpatient) and on the preference of the physician.

Treatment changes. Physicians' responses varied on how and when they wanted information on changes in a patient's treatment modes. Fifty percent wanted to be notified of any treatment changes made by the therapist. One physician thought that "it is improper [for the therapists] to strike out on their own without giving the physician a chance to reevaluate his diagnosis and treatment plan." Another physician stated that he does not "mind the therapists using their own 
judgment; that is what they went to school for. They don't need to call me unless it is really important or if they are feeling insecure about something."

All of the therapists agreed that experience was the key in knowing when or whether to notify the physician of changes in modalities they wished to use for patients. The physicians developed a trust in the therapists' knowledge and judgment after time spent working together with patients. The therapists, with time, learned the physicians' individual philosophy of treatment. Through interaction with physicians, the therapists learned when the physicians wanted to be informed about treatment changes. The therapists stated that rapport and trust take time to develop. Many of the therapists, when beginning a new job, asked the other staff therapists which physicians wanted to be notified of any treatment change. The private practitioners stated that they developed trust and rapport with physicians while they worked in a hospital setting, and they used their good relationships with physicians to establish their businesses.

Therapists most frequently telephoned physicians to change prescribed treatment, with the physician's secretary serving as an intermediary for the messages. Many of the therapists stated that they communicated more with secretaries than with physicians. The exceptions were the therapists from small rural hospitals and the therapist working in a POPTS. These three therapists spoke primarily with the physician and stated that the secretary's intermediary role was very minor. The other seven therapists expressed difficulty in contacting the physician. One therapist stated, "It can be a big problem to talk with physicians personally. They are either out of town or with a patient." One therapist suggested, "Get to know the receptionist's first name. If you develop a good rapport with her, she will keep the physician updated as to what is happening with the patient."

When asked the same question, seven out of eight physicians stated that their secretary did not play much of a role in communication with therapists. One physician said, "I usually want to talk with the therapist right away. They are professionals, and their time is valuable." Another physician stated, "I don't think they [physical therapists] should talk with my secretary. She is not 'medical' at all."

\section{Relationship Between Physical Therapists and Physicians}

Therapists generally agreed that the physician-physical therapist relationship was good or at least was improving. Therapists thought that physicians were beginning to respect them more and to realize that "their expertise is different than ours." Therapists stated that they have received more responsibility and trust from physicians over time. One therapist stated that the relationship depended on the physician. With physicians who understood physical therapy and who communicated with therapists, the professional relationship was close. With physicians who knew little about physical therapy and who did not communicate with therapists, the relationship was not close. One therapist suggested, "The ones we should be educating and communicating with are the ones who do not understand us." Another therapist stated, "It [better communication and respect] is slow coming around, and some [physicians] will never change."

More than half of the physicians stated that they viewed physical therapists as vital members of the health care team, as are nurses, dietitians, and social service personnel. The relationship was described as complementary. One physician stated, "I don't like the attitude of doctors being omnipotent." Another physician said, "A few 'bad apples' [physicians] have ruined it for a lot of people." The physicians generally were pleased with their relationships with therapists and viewed the therapists as essential health care professionals.

\section{Concerns and Problems in Communication}

Communication concerns and problems described by the physical therapists were centered around the physicians' individual style (ie, personality, availability, and dominance). The physicians had similar concerns about physical therapists. The physical therapists indicated that understanding the unique personality of each physician was important to them. One therapist said, "They all have different personalities. Some are very moody...." Another therapist stated, "It is the same complaint that patients have with doctors: You just can't talk with them." One therapist said that it takes time to get to know the physician and to learn how to communicate effectively with each one.

The physicians' lack of availability to discuss patient evaluation results and treatment recommendations was a problem for the physical therapists. Three therapists mentioned that they expended much time attempting to contact physicians. When therapists finally did get to talk with them, the interchange was too brief. Physicians, however, stated that they wanted communication from physical therapists to be concise and objective.

The physical therapists viewed physician dominance as a problem. One therapist stated, "Some physicians let you know they hold all of the cards and determine the therapist's role as a subservient one." Another therapist thought that many of the male physicians she worked with patronized her and treated her as their secretary because she is a woman. Another therapist stated that "it is the responsibility of the therapist to sense the mood [of the physician] and adjust to it." The physicians differed on their opinions of dominance in the physician-physical therapist relationship. One physician stated that he was the "captain of the ship." Another physician stated that he needed collaboration with therapists who were not afraid of or intimidated by him. Another physician commented that therapists should be involved more in the planning of the patient's treatment and that physicians had shortcomings if they did not allow that participation. Most of the physicians wanted to communicate with therapists who have a high level of expertise. They did not admit directly to patterns of behavior indicative of dominance, but they implied that physicians in general do not facilitate therapist autonomy.

\section{Communication Between Physicians and Physical Therapy Students or Recent Graduates}

All of the therapists agreed that the major communication difficulty for students and recent graduates was an unwillingness to communicate with physicians because they felt intimidated by physicians. The interviewees noted that students often do not have the experience to know when or whether they should contact the physician. One recommendation was that the primary responsibility of the physical therapy department supervisor should be to open lines of communication with physicians for the student by making personal introduc- 
tions and reinforcing appropriate independent contact by the student. Another suggestion was that the student be present during face-to-face and telephone conversations between experienced therapists and physicians to observe appropriate role modeling behavior. One therapist stated that students and recent graduates were reluctant to telephone physicians because they were afraid of being wrong or appearing not to know what they were talking about. The therapists suggested that the only way to overcome this fear is to increase the frequency of communication between physicians and students. Other suggestions by therapists were 1) to make the communication with physicians "short and sweet," 2) to contact physicians when you know they have time to talk to you, and 3) to get to know the physicians to develop trust.

The physicians thought that communication was an essential skill for therapists and that it should be developed in school. One physician suggested using role play: "Put the student in the 'hot seat' to present his or her ideas in a concise, well-organized manner, especially in a rehabilitation team setting." Two physicians mentioned the telephone as an intrusion and advised students to avoid using it indiscriminately. These physicians stated that they were kept extremely busy with patients and that even a five-minute telephone call was a bother. Other suggestions for therapists by physicians were 1) not to be intimidated by physicians; 2) to seek out the physicians whom you can communicate with easily; 3 ) to get to know your physicians and tailor your communications to their schedules; and 4) to be organized beforehand and make concise, accurate presentations.

\section{DISCUSSION}

\section{Essential Communication Areas}

The physician and the physical therapist groups both had favorable comments about the communication they had with one another. Each group, however, had different perceptions and concerns about their communication. Results of the interviews suggest that the attitudes of both physicians and physical therapists toward communication is idiosyncratic. Some physicians like contact with physical therapists, but others prefer minimal contact. Physical therapy students and recent graduates, therefore, should not expect a uniform response from physicians. As therapists, they must develop flexible social approaches so that they can alter their communication style to negotiate effectively with physicians. Students must develop the ability to be able to evaluate a communication situation and make a judgment regarding the type of communication that is most appropriate and effective (ie, assertive or collaborative).

\section{Professional Interactions}

The key interaction concept mentioned most often by both the physicians and physical therapists was the mutual trust that can be achieved through experience in working together with patients. The therapists emphasized getting to know physicians as individuals and to understand their philosophies. The physicians stated that the basis of a mutual trust relationship was a substantial amount of communication time between the physician and the therapist.

The findings of this study indicate a need to increase physicians' and therapists' awareness that stereotypes exist on both sides (eg, physicians' "captain-of-the-ship" attitude and impatience; physical therapists' lack of assertiveness and con- ciseness and their lack of awareness of the time constraints faced by physicians). Physical therapists should be encouraged to develop individual relationships with each physician that are based on perception-checking and communication competence skills. $^{12}$

\section{Recommendations for Optimal Communication}

The interviewees recommended ways for physical therapists to improve communication with physicians. These recommendations include using feedback, ${ }^{13}$ demonstrating communication competence and rhetorical sensitivity, ${ }^{10,14}$ and using assertiveness without aggressiveness. Methods for implementing these recommendations include 1) developing communication workshops for physical therapy students and new graduates with physician participation and role playing of hypothetical situations; 2) contacting physicians who are the physical therapists' primary referral sources and discussing the topics addressed in this study; 3) learning each physician's philosophy and the most effective communication and negotiation style for each; 4) suggesting that referring physicians reserve specific hours for conferences (therapists would contact physicians outside of those hours only in emergencies), thus de-emphasizing the secretary's role; and 5) establishing direct lines of communication for students and new graduates with the physicians by making personal introductions.

\section{SUMMARY}

This study was a forum for physicians and physical therapists to express their thoughts on the physician-physical therapist relationship and on the existing professional communication. We identified several problems and suggestions for areas of improvement. Although this study does not disclose or resolve all of the possible problems, it does begin to examine the topic of communication between physicians and physical therapists and emphasizes the relevance and importance of problem solving to improve the quality of patient care.

Acknowledgments. We thank Pearl Cunningham, Connie Lingle, and Denise Lewis for their inspiration, efforts, and support. 


\section{REFERENCES}

1. Yarbrough P: An Ethnography of Physical Therapy Practice: A Source For Curriculum Development. Doctoral Dissertation. Atlanta, GA, Georgia State University, 1980

2. Friedson E: Professional Dominance: The Social Structure of Medical Care. New York, NY, Atherton, 1970

3. Berger PL, Luckmann T: The Social Construction of Reality: A Treatise in the Sociology of Knowledge. New York, NY, Doubleday \& Co Inc, 1966

4. Spradley JP: Culture and Cognition: Rules, Maps and Plans. Novato, CA, Chandler \& Sharp Publishers Inc, 1972

5. Schonk-Boots L: What do you think of our physical therapy services? A questionnaire for physicians. Clinical Management in Physical Therapy 5(2):18-21, 1985

6. Ross CA, Roberts LW, Olson L: The doctor-physiotherapist relationship: The physiotherapist's perspective. Physiotherapy Canada 32:219-223, 1980

7. Stein LI: The doctor-nurse game. Arch Gen Psychiatry 16:699-703, 1967
8. Spradley JP: The Ethnographic Interview. New York, NY, Holt, Rinehart \& Winston General Book, 1979

9. Stewart CJ, Cash WB Jr: Interviewing: Principles and Practices, ed 2. Dubuque, IA, Wm C Brown Group, 1982

10. Hart RP, Carlson RE, Eadie WF: Attitudes toward communication and the assessment of rhetorical sensitivity. Communication Monographs 47(1):122, 1980

11. Miles M, Huberman A: Qualitative Data Analysis: A Sourcebook of New Methods. Beverly Hills, CA, Sage Publications Inc, 1984

12. Adler RB, Towne N: Looking Out-Looking In, ed 5. New York, NY, Holt, Rinehart \& Winston General Book, 1987

13. Wiemann JM: Explication and test of a model of communication competence. Human Communication Research 3:195-213, 1977

14. Hart RP, Burks DM: Rhetorical sensitivity and social interaction. Speech Monographs 39(2):75-91, 1972 

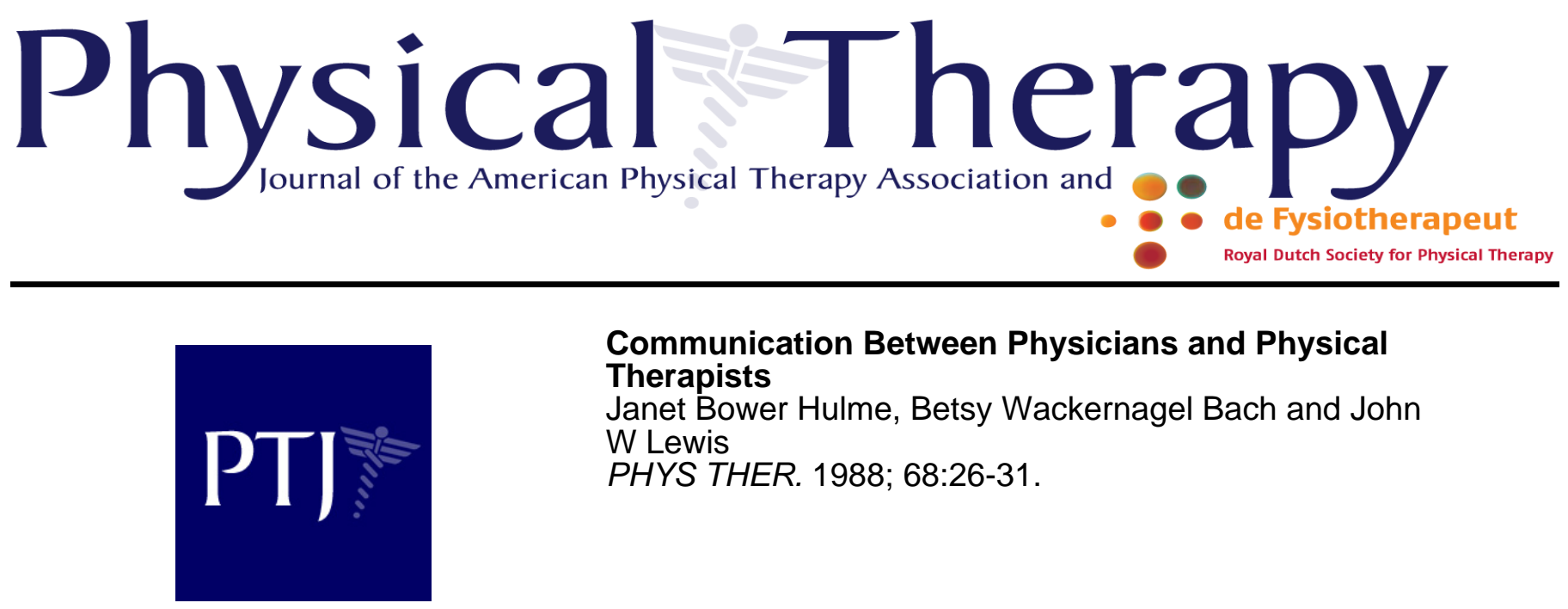

\section{Communication Between Physicians and Physical Therapists \\ Janet Bower Hulme, Betsy Wackernagel Bach and John W Lewis \\ PHYS THER. 1988; 68:26-31.}

Cited by

This article has been cited by 2 HighWire-hosted articles:

http://ptjournal.apta.org/content/68/1/26\#otherarticles

Subscription

http://ptjournal.apta.org/subscriptions/

Information

Permissions and Reprints http://ptjournal.apta.org/site/misc/terms.xhtml

Information for Authors http://ptjournal.apta.org/site/misc/ifora.xhtml 